\title{
Intraocular pressure and systemic blood pressure in the elderly
}

\author{
C. J. BULPITT, CHARLES HODES, AND M. G. EVERITT \\ From the Chronic Disease Control Study Unit, Department of Community Health, \\ London School of Hygiene and Tropical Medicine, and the \\ Theobald Centre, Borehamwood, Hertfordshire
}

The intraocular pressure rises and falls by $1 \mathrm{~mm} \mathrm{Hg}$ with every heart beat (Davson, 1972); during systole the central retinal artery compresses the accompanying vein to increase the vascular resistance in this vessel. Patients with open-angle glaucoma have been found to have a raised systemic blood pressure (Kümmell, 191 ; Vele, 1933; and Leighton and Phillips, 1972). It has been uncertain, however, whether the increased systemic blood pressure can cause a sustained increase in intraocular pressure or whether, as suggested by Leighton and Phillips, the presence of systemic hypertension compromises the capillary circulation at the optic disc and results in a clinical diagnosis of glaucoma which would otherwise be delayed or missed. Cullen, Sharp, Moore, and McCoy (1974) described a positive relationship between intraocular pressure and systemic blood pressure but the patients in their study appear to have been referred for eye examination and were not a random sample from the general population.

The results of a large survey of intraocular pressure in an elderly general population are reported in this paper. The proportion of patients with glaucoma has previously been reported (Hodes, 197I), and this present communication describes the relationship between intraocular pressure and systemic blood pressure. Also examined are the relationships between intraocular pressure, age, sex, obesity, and haemoglobin. Haemoglobin is theoretically important, as resistance in the episcleral veins can be increased by rises in blood viscosity. There are, however, no reports of increased intraocular pressure in polycythaemia, or of a low pressure in severe anaemia (Foulds, 1963), although glaucoma has been described in Waldenström's macroglobulinaemia (McLenachan, 1963).

\section{Methods}

The subjects studied were taken from 16000 patients

Address for reprints: C. J. Bulpitt, Department of Medical Statistics and Epidemiology, London School of Hygiene and Tropical Medicine, Keppel Street, London WCIE $7 \mathrm{HT}$ on the list of a group practice near London. The survey methods and response rates have been published (Hodes, 197 I). Altogether 573 patients aged over 60 years had their intraocular pressure measured using an applanation tonometer designed by Professor E. S. Perkins of the Institute of Ophthalmology (Perkins, 1965).

The age, height, and weight of the subjects were determined and the blood haemoglobin was measured using a Spence haemoglobinometer (American Optical Co.). The blood pressure was taken in the sitting position after $5 \mathrm{~min}$ rest, using a standard mercury sphygmomanometer. Trained nursing staff took the diastolic pressure at the point of muffling of sound.

\section{STATISTICAL METHODS}

The intraocular pressure in both eyes, systolic and diastolic blood pressure, haemoglobin, age, weight, and height were tested for normality. Each variable was approximately normally distributed. A ponderal index was calculated as height in inches divided by the cube root of weight in pounds (Livi, 1897).

The relationship between intraocular pressure and the other variables was assessed using multiple regression techniques. Individually, the right and left intraocular pressures and the sum of the two pressures were regressed on sex (SEX $=1=$ male, sEX $=2=$ female), age in years (AGE), systolic blood pressure in $\mathrm{mm} \mathrm{Hg}$ (SBP), diastolic pressure (DBP), blood haemoglobin (Hb), height in inches (HT), weight in lbs (WT) and ponderal index (PON).

Certain variables were not determined for every subject, and initial regression was performed only for those who had a complete set of data. Variables not reaching the 5 per cent significance level were eliminated from the regression, and the final equations used only 'significant' variables, and included all subjects in whom these final variables had been determined.

\section{Results}

Table I shows the range, mean, and standard deviation for each of the variables measured, and the mean results for both men and women. The range of intraocular pressure was considerable, 3-36 $\mathrm{mm} \mathrm{Hg}$, and there was also a wide range of systemic blood pressure, systolic 86-286 mm Hg, 
Table I Mean, range, and standard deviation of a single observation for variables measured. Mean results subdivided according to sex (men $22 \mathrm{I}$, women 352)

\begin{tabular}{|c|c|c|c|c|c|c|c|c|}
\hline \multirow{2}{*}{ Variables } & \multirow{2}{*}{ Mean } & \multicolumn{2}{|c|}{ Range } & \multirow{2}{*}{ No. } & \multirow[b]{2}{*}{$\begin{array}{l}\text { Standard } \\
\text { deviation }\end{array}$} & \multicolumn{2}{|l|}{ Mean } & \multirow{2}{*}{$\begin{array}{l}\text { Significance } \\
\text { of sex } \\
\text { difference }\end{array}$} \\
\hline & & Low & High & & & Men & Women & \\
\hline \multicolumn{9}{|l|}{ Intraocular pressure $(\mathrm{mm} \mathrm{Hg})$} \\
\hline Right & 14.9 & 3 & 29 & 568 & 3.5 & $14 \cdot 6$ & $15^{1} 1$ & NS \\
\hline Left & $15 \cdot 3$ & 4 & 36 & 571 & 3.5 & $15 \cdot 2$ & $15 \cdot 4$ & NS \\
\hline \multicolumn{9}{|l|}{ Systemic blood pressure $(\mathrm{mm} \mathrm{Hg})$} \\
\hline Systolic & $157 \cdot 8$ & 86 & 268 & 573 & $29 \cdot 9$ & 147 & 163 & $P<0.001$ \\
\hline Diastolic & $85 \cdot 5$ & 46 & 148 & 573 & $15 \cdot 0$ & 82 & 88 & $P<0.001$ \\
\hline Weight (lb) & 143.9 & 84 & 241 & 569 & $26 \cdot 0$ & 153 & 139 & $P<0.001$ \\
\hline Height (in) & $63 \cdot 3$ & 56 & 78 & 566 & $3 \cdot 6$ & 67 & 61 & $P<0.001$ \\
\hline Age (yr) & $72 \cdot 1$ & 60 & 96 & 573 & $7 \cdot 6$ & $70 \cdot 7$ & $73 \cdot 3$ & $P<0.001$ \\
\hline Haemoglobin $(\mathrm{g} / \mathrm{1} 00 \mathrm{ml})$ & 13.4 & $8 \cdot 7$ & 17.8 & 376 & $1 \cdot 3$ & $13 \cdot 7$ & $13 \cdot 0$ & $P<0.001$ \\
\hline
\end{tabular}

and diastolic 46-148 $\mathrm{mm} \mathrm{Hg}$. Patients with abnormal results were not excluded from this general population. The mean intraocular pressure was not significantly different between the sexes but the systemic blood pressure was significantly higher in women and weight, height, and haemoglobin were greater in the men.

Table II shows the first order correlation coefficients for 370 patients in whom all the variables had been measured. The best correlations between intraocular pressure and other variables were with systolic and diastolic pressure, ponderal index (weight corrected for height), and weight. The higher the blood pressure the greater the intraocular pressure, and similarly, the more obese the patient the higher the intraocular pressure. Intraocular pressure was not significantly related to sex, age, height, or haemoglobin.

Blood pressure was correlated with obesity and it is important to confirm that the two variables exert independent effects on intraocular pressure. The variables were therefore included in multiple regression equations to predict the intraocular pressure for the left and right eyes and the average pressure for the two eyes. The results are given in Table III, and the equation for average intraocular pressure in $\mathrm{mm} \mathrm{Hg}(Y)$ was:

$$
Y=16.79+0.023 \text { SBP }-0.44 \text { PON }
$$

( $\mathrm{n}=555$, both systolic pressure (SBP) and ponderal

Table II First-order correlation coefficients for 370 patients in whom all variables are known

\begin{tabular}{|c|c|c|c|c|c|c|c|c|c|c|c|c|}
\hline \multirow[b]{2}{*}{ Variables } & & \multirow[b]{2}{*}{$P_{R}$} & \multirow[b]{2}{*}{$P_{L}$} & \multirow[b]{2}{*}{$\begin{array}{l}P_{R}+ \\
P_{L} \\
\end{array}$} & \multirow[b]{2}{*}{$\operatorname{Sex}$} & \multirow[b]{2}{*}{ Age } & \multicolumn{2}{|c|}{ Blood pressure } & \multirow[b]{2}{*}{ Height } & \multirow[b]{2}{*}{ Weight } & \multirow[b]{2}{*}{$\begin{array}{l}\text { Ponderal } \\
\text { index }\end{array}$} & \multirow[b]{2}{*}{$\begin{array}{l}\text { Haemo- } \\
\text { globin }\end{array}$} \\
\hline & & & & & & & Systolic & Diastolic & & & & \\
\hline $\begin{array}{l}\text { Intraocular pressure }(\mathrm{mm} \mathbf{H g}) \\
\mathbf{P}_{\mathbf{R}}+\mathbf{P}_{\mathbf{L}}\end{array}$ & $\begin{array}{l}\text { Right }\left(\mathbf{P}_{\mathbf{R}}\right) \\
\text { Left }\left(\mathbf{P}_{\mathbf{L}}\right)\end{array}$ & $\mathbf{I}$ & $\begin{array}{l}0.82 * * * 1 \\
1\end{array}$ & $\begin{array}{l}0.96 \\
0.95 \\
1\end{array}$ & $\begin{array}{l}0.08 \\
0.06 \\
0.08 \\
\end{array}$ & $\begin{array}{l}0.08 \\
0.03 \\
0.06 \\
\end{array}$ & $\begin{array}{l}0.31^{* * *} \\
0.27^{* * *} \\
0.30^{* * *}\end{array}$ & $\begin{array}{l}0.27^{* * *} \\
0.22^{* * *} \\
0.26^{* * *}\end{array}$ & $\begin{array}{l}-0.09 \\
-0.08 \\
-0.09\end{array}$ & $\begin{array}{l}0.12^{*} \\
0.09 \\
0.11^{*}\end{array}$ & $\begin{array}{l}-0.20^{* * *} \\
-0.16^{* * *} \\
-0.18 * *\end{array}$ & $\begin{array}{l}0.00 \\
0.01 \\
0.01\end{array}$ \\
\hline $\begin{array}{l}\text { Sex: } \begin{array}{l}\text { Male I } \\
\text { Female 2 }\end{array} \\
\end{array}$ & & & & & $\mathbf{I}$ & $0.12^{*}$ & $0.24^{* * *}$ & $0.18^{* *}$ & $-0.68^{* * *}$ & $-0.23^{* * *}$ & $-0.39^{* * * *}$ & $-0.29^{* * *}$ \\
\hline Age (yr) & & & & & & I & $0.15^{* *}$ & -0.03 & $-0.27^{* * *}$ & $-0 \cdot 17^{* *}$ & -0.07 & $-0.17^{* *}$ \\
\hline Blood pressure $(\mathrm{mm} \mathrm{Hg})$ & $\begin{array}{l}\text { Systolic } \\
\text { Diastolic }\end{array}$ & & & & & & $\mathbf{I}$ & $\begin{array}{l}0.74 * * * \\
1 \\
\end{array}$ & $\begin{array}{l}-0.20 * * * \\
-0.17^{* *} \\
\end{array}$ & $\begin{array}{l}0.02 \\
0.08 \\
\end{array}$ & $\begin{array}{l}-0.19 * * \\
-0.23 * * * \\
\end{array}$ & $\begin{array}{r}-0.04 \\
0.05 \\
\end{array}$ \\
\hline Height (in) & & & & & & & & & $\mathbf{I}$ & $0.41 * * *$ & 0.51 & $0.22^{* *}$ \\
\hline Weight (lb) & & & & & & & & & & $\mathbf{I}$ & -0.56 & $0.20^{* *}$ \\
\hline Ponderal index & & & & & & & & & & & $\mathbf{I}$ & 0.00 \\
\hline Haemoglobin $(\mathrm{g} / \mathrm{r} 00 \mathrm{ml})$ & & & & & & & & & & & & $\mathbf{I}$ \\
\hline
\end{tabular}


Table III Partial regression coefficients of independent variables

\section{Independent variables}

\begin{tabular}{|c|c|}
\hline \multicolumn{2}{|l|}{$\begin{array}{l}\text { Haemoglobin } \mathrm{g} / 100 \mathrm{ml} \\
\text { Sex: Male I } \\
\text { Female } 2\end{array}$} \\
\hline Age (yr) & \\
\hline Height (in) & \\
\hline Weight (lb) & \\
\hline Ponderal index & \\
\hline Blood pressure (mm Hg) & $\begin{array}{l}\text { Systolic } \\
\text { Diastolic }\end{array}$ \\
\hline $\begin{array}{l}\text { Constant } \\
\text { Multiple R }\end{array}$ & \\
\hline
\end{tabular}

No. of cases
Intraocular pressure ( $\mathrm{mm} \mathrm{Hg}$ )

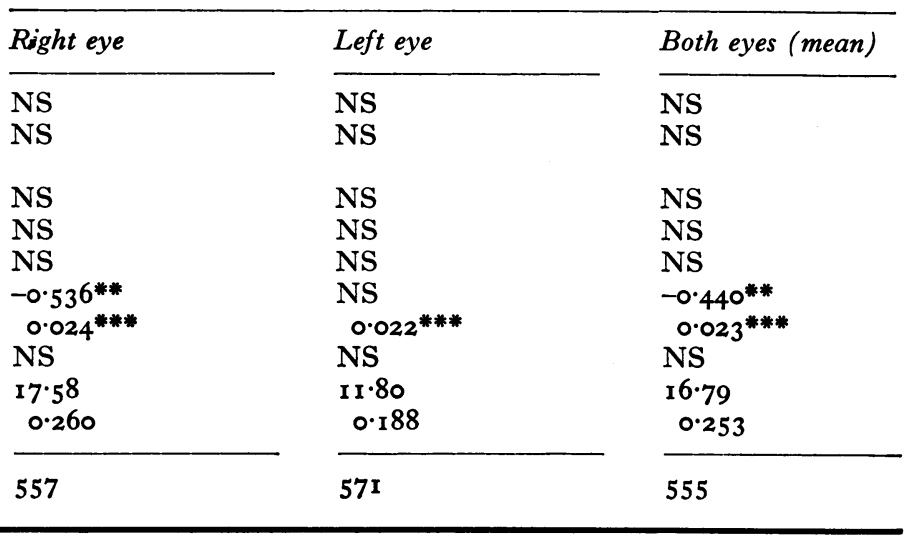

NS-Not significant

**P $<0.01$

$* * * P<0.001$ index (PON) regression coefficients were significant at the 0.1 - I per cent level).

The inclusion of systolic pressure and ponderal index in the equation explained 6 per cent of the variation in intraocular pressure. Haemoglobin, sex, age, height, weight, and diastolic pressure did not contribute any significant additional information in the prediction of average intraocular pressure. Similarly systolic pressure was more closely correlated with intraocular pressure than either the pulse pressure (SBP-DBP) or mean blood pressure

$$
\left(\mathrm{DBP}+\frac{\mathrm{SBP}-\mathrm{DBP}}{3}\right) .
$$

\section{Discussion}

Both systolic blood pressure, as measured in the arm, and obesity (the smaller the ponderal index the more obese the patient) were positively and independently correlated with intraocular pressure.

Systolic pressure was more closely correlated with intraocular pressure than diastolic, mean, or pulse pressure. The height of the pressure wave reaching the eye may therefore be a more important determinant of intraocular pressure than the perfusion pressure. For a $100 \mathrm{~mm} \mathrm{Hg}$ increase in systolic pressure there was a $2 \mathrm{~mm} \mathrm{Hg}$ rise in intraocular pressure. This is not clinically significant and it may be difficult to demonstrate an increased incidence of raised intraocular pressure in hypertensive patients. The association does, however, indicate a functional relationship between systemic blood pressure and intraocular pressure, and implies that the higher average blood pressure of open-angle glaucomatous patients is not due to enhanced diagnosis of glaucoma in patients with hypertension.

The intraocular pressure may have been increased by four mechanisms:

I. Increased retinal blood volume after a rise in central retinal vein pressure because of increased pressure in the adjacent central retinal artery.

2. Increased blood volume in the ciliary body and decreased facility of aqueous outflow owing to an increase in resistance in the episcleral and anterior ciliary veins.

3. Increased filtration of aqueous fluid in the ciliary body owing to the increased perfusion pressure in the ciliary arteries.

4. Obstruction to aqueous drainage at the anterior chamber angle.

Increases in intraocular pressure after changes in retinal venous pressure may in time revert to normal. In the rabbit Bárány (1947) showed that the fall in intraocular pressure induced by ligating the common carotid was not maintained. The first explanation would therefore appear unlikely; nor does the second explain the relationship between systemic and intraocular pressure, as a rise in systemic arterial pressure is unlikely to increase the pressure in the ciliary veins.

An increased systemic pressure will, however, increase the amount of aqueous fluid filtered through the ciliary body although probably affecting the amount produced by filtration and not active secretion (Macri, 1967). The increase in intraocular pressure will then decrease the amount of aqueous fluid filtered and the intraocular pressure will be set at a new and higher level. The third theory 
would therefore appear to be the most likely explanation of the direct relationship between intraocular and systemic pressure.

Leighton and Phillips (1972) showed that intraocular pressure was positively related to diastolic pressure in 22 cases of both open-angle and 'low tension' glaucoma, but that the theoretical perfusion pressure (mean systemic pressure less intraocular pressure) was the same in high tension cases as in the controls. This assumes an increase of $\mathrm{I} \mathrm{mm}$ in intraocular pressure for every $1 \mathrm{~mm}$ increase in perfusion pressure, a 'one to one' relationship not found in the present study. Moreover Cullen and others (1974) found a 6-7 $\mathrm{mm} \mathrm{Hg}$ rise in intraocular pressure for a $100 \mathrm{~mm} \mathrm{Hg}$ increase in systolic pressure, and it is possible that patients with an ophthalmic disorder may show a closer relationship between systemic and intraocular pressure than the general population.

Obesity could be positively related to intraocular pressure if lipid deposits reduced the facility of outflow for aqueous fluid (the fourth explanation) and the observations in this paper require confirmation by measurements of the aqueous outflow facility in obese patients.

Although the packed cell volume and haemoglobin are positively related to blood viscosity and hence to vascular resistance in the episcleral veins, it is of interest that no relationship between haemo- globin and intraocular pressure could be detected in this study. This may be because of the dilution of blood by aqueous fluid in the episcleral veins.

\section{Summary}

The intraocular and systemic blood pressure, height, weight, and haemoglobin were measured in 573 subjects over 60 years old from a general practice population. Intraocular pressure was positively and independently related to systemic blood pressure $(\mathrm{P}<0.001)$ and obesity $(\mathrm{P}<0.01)$ as assessed by the ponderal index. Systolic pressure rather than diastolic or mean pressure was most closely correlated with intraocular pressure and it is suggested that the systolic head of pressure increases the filtrated fraction of aqueous humour to cause a small but sustained rise in intraocular pressure. It is also suggested that obesity may decrease the facility of aqueous outflow.

The work was supported in part by a grant from the DHSS. We are indebted to Mrs P. A. Love and Mrs M. Wallis for nursing assistance. We also wish to thank all the staff of the group practice where the survey was conducted, and Professor E. S. Perkins, Institute of Ophthalmology, and Professor J. N. Morris, Head of Department of Community Health, London School of Hygiene and Tropical Medicine, for their support and advice.

\section{References}

BÁRÁNY, E. (1947) Acta. ophthal. (Kbh.), 25, 8 I

CUllen, A. P., SHARP, H. R., MOORE, s. v., and MCCOY, D. E. (1974) Amer. F. Optom., 5I, 4I4

DAvson, H. (1972) In 'Physiology of the Eye', 3rd ed. Churchill Livingstone, Edinburgh and London

Foulds, w. S. (1963) Trans. ophthal. Soc. U.K., 83, 345

hodes, C. (1971) f. roy. Coll. gen. Practit., 2r, 469

KüMMELL, R. (I9I I) v. Graefes Arch. Ophthal., 79, I83

LEIGHTON, D. A., and PHILlips, C. I. (1972) Brit. F. Ophthal., 56, 447

LIVI, R. (1897) Atti. Soc. rom. Antrop., 5, 125

MCLENACHaN, J. (1963) Trans. ophthal. Soc. U.K., 83, 36r

MACRI, F. J. (1967) Arch. Ophthal. (Chicago), 78, 629

PERKINS, E. S. (1965) Brit. med. F., r, 417

VELE, M. (1933) Ann. Ottal., 6r, 51 I 